\title{
CONGENITAL PULMONARY STENOSIS
}

\section{WITH LEFT VENTRICULAR ENLARGEMENT ASSOCIATED WITH - ATRIAL SEPTAL DEFECT}

\author{
BY \\ PAUL WOOD \\ From the Department of Medicine, British Postgraduate Medical School, Hammersmith \\ Hospital, London \\ Received December 6, 1941
}

Observations on the morbid anatomy of congenital heart disease are in advance of clinical studies, and although we have been supplied by pathologists with much information about the meaning and incidence of the various single or combined developmental abnormalities of the heart, such knowledge is of practical value to the clinician only when he can recognize them during life. Certain well defined, single or combined, lesions may now be easily diagnosed at the bedside, especially with the aid of X-ray and electrocardiographic examination. It is the object of this report to present the clinical features of another congenital syndrome which, if not a freak, may prove recognizable at the bedside.

It is well known that marked pulmonary stenosis, as part of the tetralogy of Fallot or otherwise, causes enlargement of the right ventricle and deviation of the electrical axis of the heart to the right. It is also well known that patency of the interauricular septum produces progressive enlargement of the right ventricle, and right axis deviation or even right bundle branch block. It is interesting, therefore, that a combination of these two lesions may apparently result in left ventricular enlargement and left axis deviation. These effects are illustrated by the following case.

\section{DESCRIPTION OF CASE}

A girl, aged 6, was first seen by me in April, 1935. She had been cyanosed from birth, and had never been able to walk. She did not sit up until she was two, and since then had only been able to shuffle about on her buttocks. Her mental development was normal at first, for she began to talk when she was one, and spoke short sentences at one and a half. Because of her legs she had to be carried about, and it was soon noticed that if she were held upright suddenly, or if she exerted herself too strenuously, she was subject to fainting attacks, in which she turned deep blue, gasped for breath, and finally lost consciousness. Recovery occurred in about a minute, and there were no convulsions. From the age of four she also suffered from severe right-sided headaches, which caused her to scream for an hour or so, and of which she had no recollection. During the fortnight preceding admission to hospital, her speech became slurred and difficult to understand, and excessive salivation was bothersome.

Her parents were healthy, and there were six other children, alive and well.

Examination revealed a very cyanosed child with clubbing of the fingers and toes 


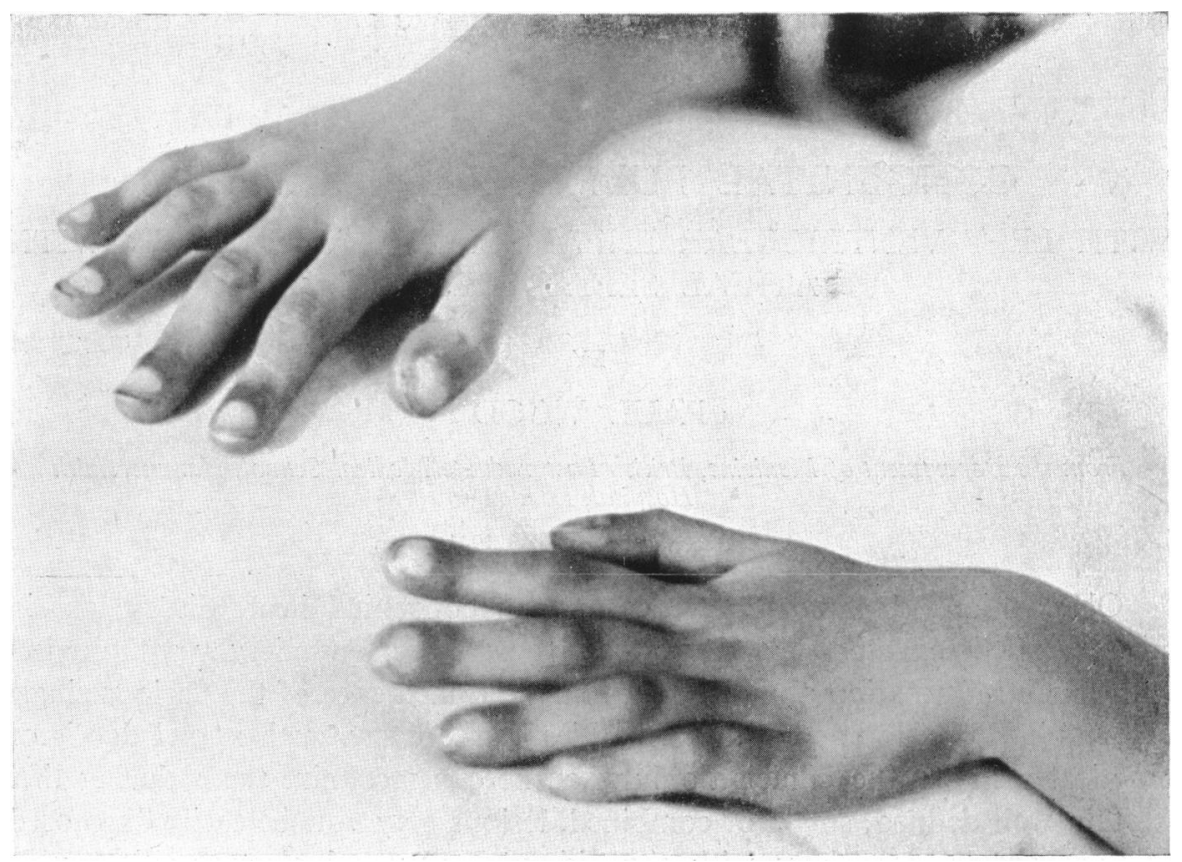

FIG. 1.-Clubbed fingers.

(Fig. 1). She was in no distress, and there was no dyspnœa. The temperature was normal, the pulse rate 100 beats per minute, and the respiration rate 20 per minute. There was no focal or general infection.

Cardiovascular system. The heart was central in position, a diffuse cardiac impulse being felt as much to the right as to the left of the sternum. There were no thrills, but there was a loud and significant systolic bruit, heard rather better to the right than to the left of the mid-line, and of maximum intensity at the level of the second and third interchondral spaces. It seemed to be conducted into the vessels of the neck. The second heart sound at the base was sharp and clear, and could be heard equally well on either side of the sternum. The heart sounds were not remarkable elsewhere.

The rhythm was normal, the cervical veins were not engorged, the liver was impalpable, there was no œdema, and there was no evidence of pulmonary congestion. The blood pressure varied between 125/90 and 110/85. All the main arteries of the limbs were normal to palpation.

An electrocardiogram (Fig. 2) showed left axis deviation, and $\mathbf{P}$ waves which were split, up to $0 \cdot 10-0.12 \mathrm{sec}$. in duration, prominent in lead I, and inverted in lead III.

The skiagram (Fig. 3) and radioscopy revealed marked prominence of the ascending aorta, left ventricular dominance, and displacement of the whole heart to the right.

A blood count showed 10,400,000 red cells per c.mm., hæmoglobin 108 per cent, white cells 3400,39 per cent of which were polymorphonuclear cells.

Central nervous system. There was a combination of left hemiplegia and paraplegia: there was weakness of the left side of the face, the palate was drawn up to the right, the tongue was protruded to the left, the left arm was weak, and both legs were spastic, with exaggerated tendon jerks and bilateral extensor plantar responses. There was no sensory loss.

Apart from the cardiovascular and nervous systems there were no other abnormalities, except a palpable spleen. 


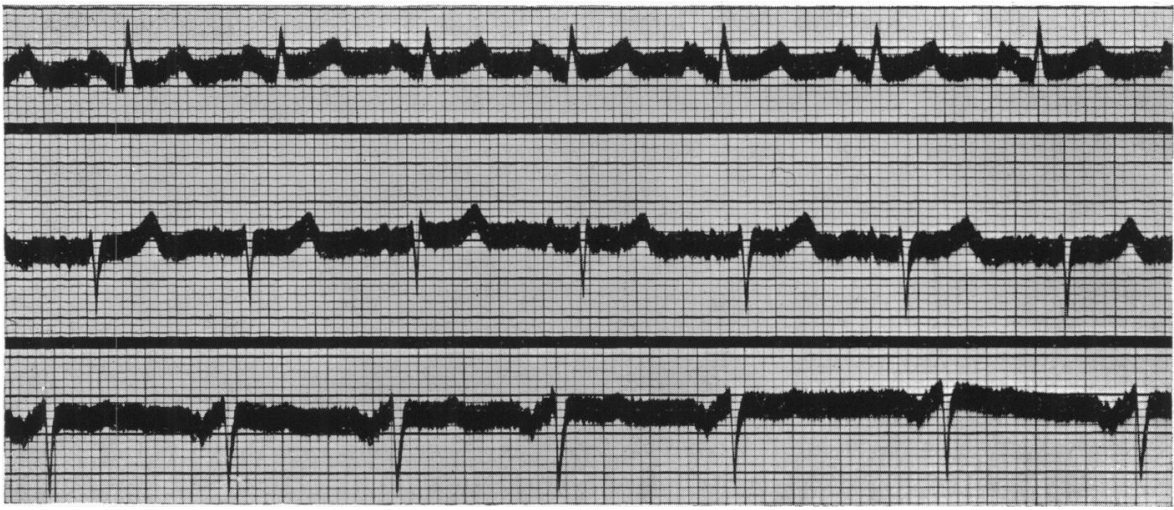

FIG. 2.-Electrocardiogram_of case, showing left]axis"deviation.

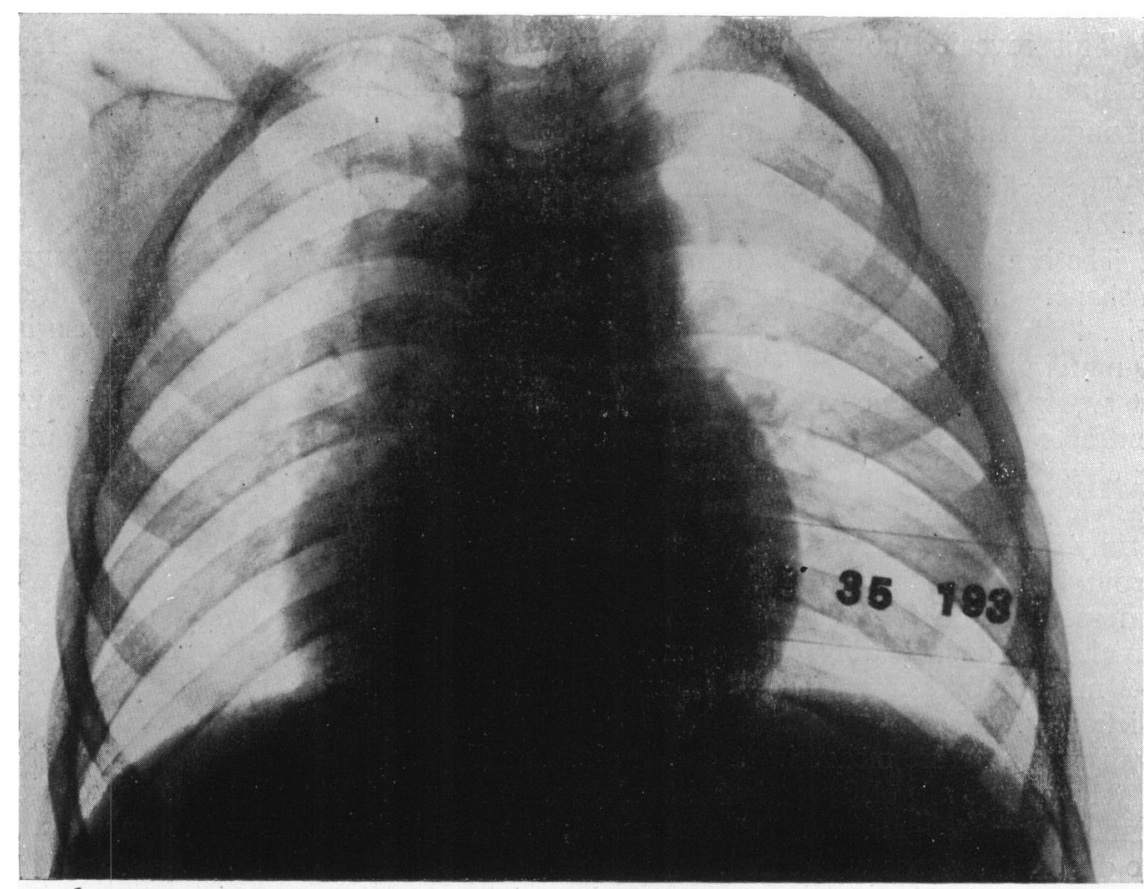

FIG. 3.-Teleradiogram of heart: note the central position, the prominence of the ascending aorta, the shadow external to the ascending aorta (probably the superior vena cava), and the rounded, bulky left ventricle.

The diagnosis was congenital heart disease with permanent cyanosis, clubbing, and polycythæmia, but the exact lesion or combination of lesions could not be determined. For while the clinical features suggested marked pulmonary stenosis or atresia, the X-ray and cardiographic evidence left little doubt that the left side of the heart was carrying the burden.

The subsequent course threw no further light on the matter. She was observed for nearly two years, and repeated clinical, radioscopic, and cardiographic examinations merely confirmed the above findings. On one occasion 
she was admitted with athetoid movements of the right arm, when her blood count was as high as $11,200,000$ red cells per c.mm., and the hæmoglobin 124 per cent. At that time it was shown that the viscera were not transposed. On another occasion, night sweats, general malaise, slight fever, a palpable spleen, and a few granular casts and red cells in the urine, made me suspect superimposed bacterial endocarditis. The blood urea was $30 \mathrm{mg}$. per 100 c.c., the specific gravity of the urine varied between 1005 and 1025 , and there was no albuminuria. A blood culture was not obtained.

On March 5, 1937, she was readmitted with frequent syncopal attacks associated with deepened cyanosis, and on March 29 she died in one of them. These attacks were similar to those of which she had complained for many years, and which have already been described. At this time she was eight years old.

\section{Post-Mortem Examination}

This revealed congenital pulmonary valvular stenosis, atrial septal defect, dominant hypertrophy of the left ventricle, and intense venous congestion throughout all the viscera, but especially marked in the meninges and brain.

The body was that of a well nourished female child: the weight was $36 \mathrm{lb}$; the height, $4 \mathrm{ft}$.

The heart weighed $182 \mathrm{~g}$. (normal for this age 95-105 g.). It was almost square in shape. The aorta was prominent, and the dominant chamber was the left ventricle (Fig. 4 and 5). This was dilated and considerably hypertrophied, its wall measuring $10 \mathrm{~mm}$. in thickness at the apex, $16 \mathrm{~mm}$. at the centre, and $18 \mathrm{~mm}$. at the base. The interventricular septum bulged to the right, and was intact. The right ventricle was contracted, and its wall measured $12 \mathrm{~mm}$. at the site of the moderator band, $8.5 \mathrm{~mm}$. on either side of it, and $6 \mathrm{~mm}$. at the base. The outflow tract of the right ventricle was elongated and narrow. The pulmonary valve (Fig. 4) consisted of two cusps, mainly fused together, leaving a narrow aperture slightly less than $5 \mathrm{~mm}$. in diameter. Around the free margin of the cusps was a ring of granular, wart-like, vegetations, composed microscopically of hyaline thrombi without cellular reaction. The left auricle was considerably dilated and somewhat hypertrophied, its wall measuring 1-2 mm. in thickness. The right auricle was also enlarged, but a little less conspicuously. There was a large defect of the atrial septum, at the site of the fossa ovalis, the aperture measuring $2 \mathrm{~cm}$. in diameter (Fig. 5).

The aortic, mitral, and tricuspid valves were normal. There was no coarctation of the aorta; the great vessels were normal; the coronary arteries were normal; and the ductus arteriosus was closed.

Microscopically, the muscle fibres of the left ventricle were thicker than those from any other chamber. Apart from some increased cellularity of the interstitium, and a trace of perivascular fibrosis here and there, there were no significant microscopic changes.

The other autopsy findings simply showed the effects of intense venous congestion, all the viscera being involved. The bone marrow was very hyperplastic, and microscopically this was shown to be due to normoblastic proliferation. The meninges over the whole of both hemispheres were intensely vascular and deeply congested, the vessels lying so close together as to be almost touching. The vascularity and congestion were such as to form a deep purple membrane, through which the underlying brain could not be seen. The grey matter of the brain, over practically the whole of both hemispheres, showed a fine granularity, and one section was deeply congested. On the posterior lateral aspect of the left occipital lobe there was an 


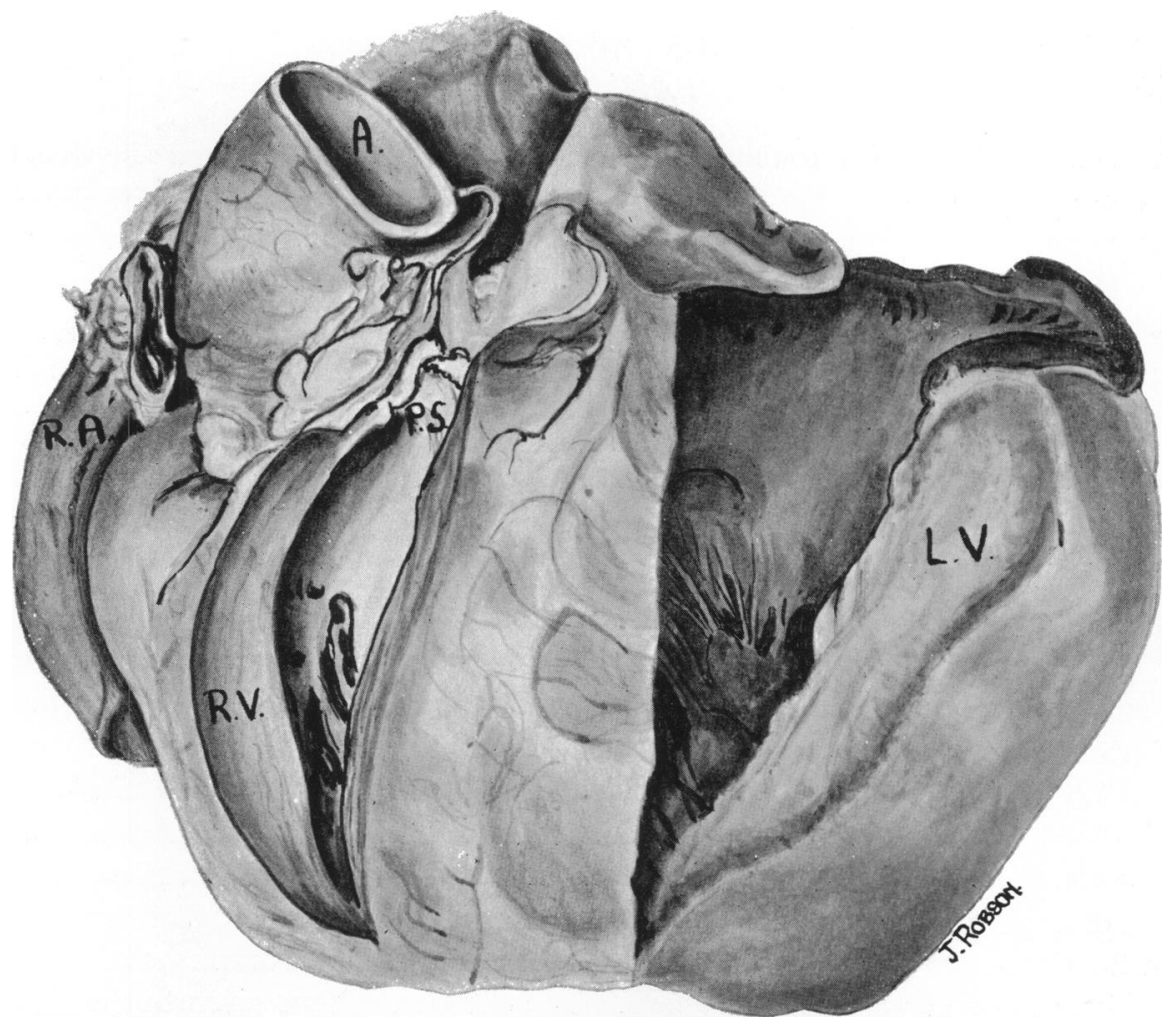

(2)

Fig. 4.-Drawing of the heart (to scale) from the front: A., aorta; L.V., left ventricle; P.S., pulmonary stenosis; R.V., right ventricle; R.A., right auricle.

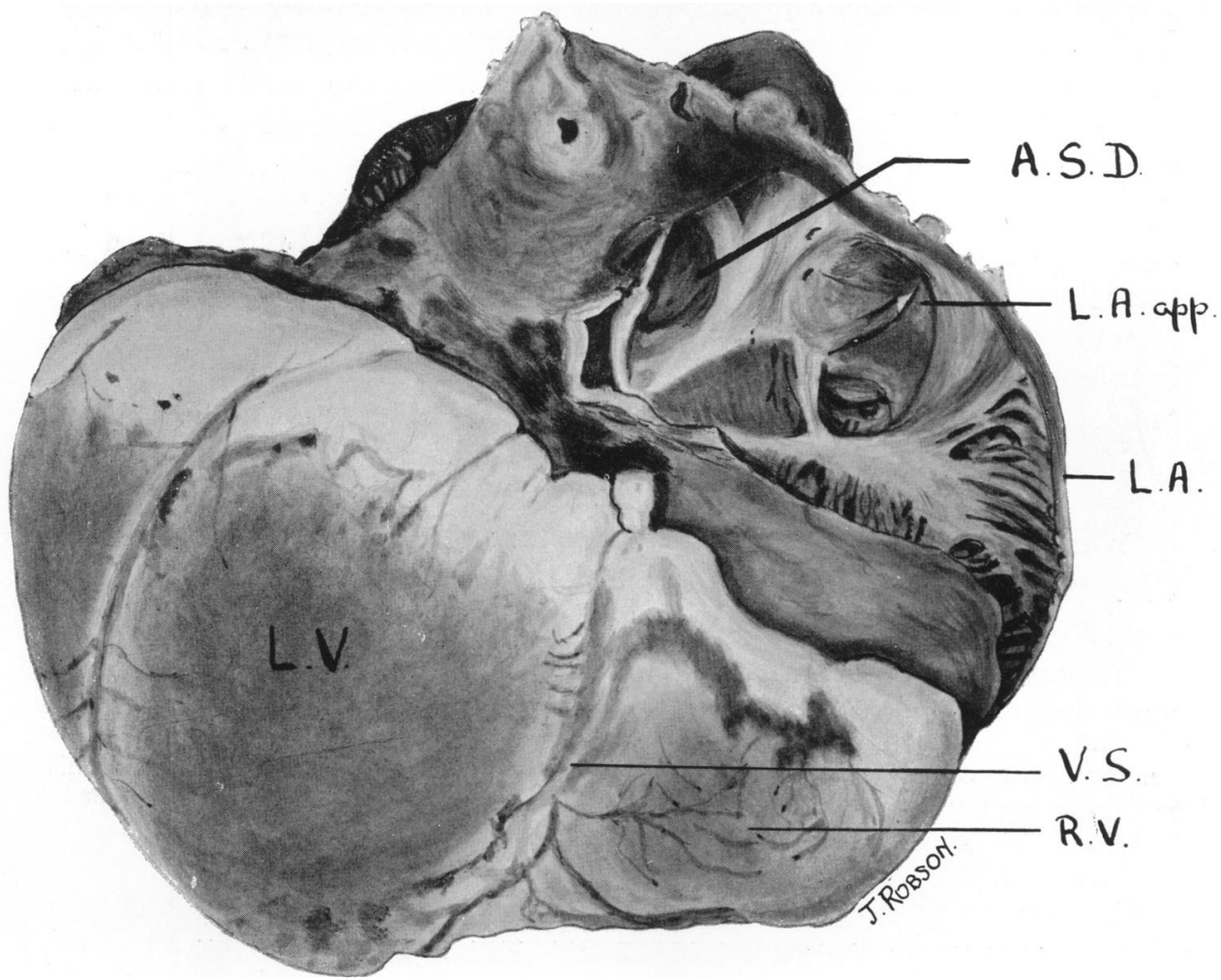

Fig. 5.-Drawing of the heart (to scale) from behind: L.V., left ventricle; R.V., right ventricle; L.A., left auricle; L.A. app., left auricular appendage; A.S.D., atrial septal defect at site of fossa ovalis. 
area of softening, limited to the grey matter, which in this area was practically absent, being represented by a little semi-fluid matter. The pons, medulla, and cerebellum were less affected than the rest of the brain. The white matter appeared normal throughout.

Dr. Greenfield kindly examined the sections of the brain and meninges, and concluded that all the changes could be attributed to intense congestion. Some of the nerve cells were indistinct and shrunken. The nuclear chromatin had lost its normal pattern, and stained darkly and diffusely. The nucleolus was not, as a rule, visible. In some areas there was complete disappearance of all nerve cells. There was no apparent gliosis or other change. In the occipital lobe, the softened area previously described, consisted of collapsed neuroglial reticulum devoid of nerve cells.

\section{Discussion}

It is clear that this was a case of pulmonary valvular stenosis complicated by wide patency of the interauricular septum, there being no other abnormalities. Uncomplicated atrial septal defect is held to be responsible for the gross enlargement of the chambers on the right side of the heart which is associated with it (Bedford, Papp, and Parkinson, 1941). In these cases it is believed that there is a considerable shunt of blood from the left to the right auricle, there being reason to think that the pressure in the left auricle is normally higher than that in the right-for consider the mechanism of closure of the foramen ovale, and the behaviour of paradoxical emboli. The extra work thus given to the right side of the heart is the simplest explanation of the great enlargement found. The sudden development of extreme cyanosis when the right ventricle begins to fail is readily understood on the supposition that the rising pressure in the right auricle effects a reversal of flow through the atrial septal defect. In the case recorded here, extreme cyanosis was lifelong, and the left side of the heart was most enlarged, facts which indicate that the shunt was perpetually from right to left. It follows that the pressure in the right auricle must have been higher than that in the left. It is not obvious why this should have been so, for right ventricular failure was not clinically apparent. Had tricuspid stenosis been present as a congenital defect the case would have presented no difficulties, but the tricuspid valve was normal. One is driven to the conclusion that the pulmonary stenosis was responsible for the raised pressure in the right auricle.

\section{SUMmaRY}

A case is described which presented the following features:

(1) pulmonary valvular stenosis, (2) atrial septal defect, (3) left ventricular dominance, and (4) extreme permanent cyanosis.

The question arises whether this will prove a clinically recognizable congenital syndrome, or whether this is a freak case.

My thanks are due to the chief medical officer of the London County Council for his permission to publish this case; and I wish to express my appreciation and gratitude to Mr. J. Robson for his careful drawings of the heart.

REFERENCE

D. E. Bedford, C. Papp, and J. Parkinson. Brit. Heart J. (1941), 3, 37 i i 